\title{
DISTRIBUIÇÃO, MORFOLOGIA E ANATOMIA DE MONILÓFITAS (SAMAMBAIAS) AQUÁTICAS DE PEQUENAS LAGOAS NA ÁREA ITAQUI-BACANGA, ILHA DE SÃO LUÍS - MA
}

\author{
Ricardo Barbieri1 ${ }^{1 D}$, Lenise Bruna Carvalho Lima1, Maria Marlúcia Ferreira Correia \\ ${ }^{1}$ Departamento de Oceanografia e Limnologia, Universidade Federal do Maranhão, Av. dos Portugueses, 1966 - \\ Campus Universitário do Bacanga, 65080-805 - São Luís - MA. Autor correspondente: limnobarbi@yahoo.com.br
}

\section{RESUMO}

Foi verificada a distribuição, feita a identificação taxonômica e a caracterização morfológica das espécies de monilófitas (samambaias) aquáticas de quatro lagoas pequenas temporárias e duas perenes localizadas ao longo da estrada que corta o setor industrial da área Itaqui-Bacanga, na ilha de São Luís - MA, durante o período de junho a setembro de 2011. As espécies encontradas nos ambientes amostrados foram Salvinia auriculata, Salvinia molesta (Salviniaceae) e Ceratopteris thalictroides (Pteridaceae). As três espécies apresentaram caráter de ocorrência anual e as Salviniaceae estiveram amplamente distribuídas nos ambientes aquáticos observados. Dentre as monilófitas amostradas, apenas o gênero Salvinia apresenta heterosporia, com a presença de megasporângios e microsporângios. O gênero Ceratopteris, por sua vez, é homosporado, apresentando apenas esporos masculinos, que possuem um potencial para desenvolver gametófitos que futuramente poderão ser masculinos ou hermafroditas. A superfície foliar (tricomas), no caso de Salvinia, e o caule, no caso de Ceratopteris, são importantes estruturas na flutuabilidade das plantas. As três espécies apresentam adaptações morfológicas fundamentais para o seu estabelecimento e desenvolvimento nesses locais. Palavras-chave: eufilófitas aquáticas, ocorrência, adaptações morfológicas, lagoas.

\section{ABSTRACT}

\section{Distribution, morphology and anatomy of aquatic Monilophyta (ferns) in small ponds at the area Itaqui-Bacanga, São Luís Island-MA}

Distribution, taxonomic identification and morphological analysis of aquatic species of Monilophyta (ferns) were carried out in four perennial and two temporary ponds located along the road through the industrial area Itaqui-Bacanga, at the São Luís Island-MA, from June to September 2011. The species found in the study sites were Salvinia auriculata, Salvinia molesta (Salviniaceae) and Ceratopteris thalictroides (Pteridaceae), all presenting an annual occurrence in nature and Salviniaceae were widely distributed in the ponds observed. Among the monilophytes sampled, only the Salvinia genus shows heterosporia, with the presence of megasporangia and microsporangia. The genus Ceratopteris in turn is homosporate, presenting only male spores, which have a potential to develop gametophytes that in the future may be male or hermaphrodite. The leaf surface (trichomes), in the case of Salvinia, and the stem, in the case of Ceratopteris, are important structures in the buoyancy of plants. The three species show important morphological adaptations for their establishment and development in these places.

Key words: aquatic Euphillophyta, occurrence, morphological adaptations, ponds.

\section{INTRODUÇÃO}

As Euphyllophyta-Monilophyta ou samambaias na nova nomenclatura botânica (Zuquim et al., 2008; Gissi, 2016), Pteridophyta segundo Tryon \& Tryon (1982, cit. em Pereira, 2003), constituem um grupo relativamente importante, pois possuem entre 12.000 e 14.000 espécies em todo o mundo e cerca de 3.250 ocorrem nas Américas. De acordo com Prado (1998), estima-se que no Brasil ocorram entre 1.200 e 1.300 espécies, abrigando, inclusive, um dos centros de endemismo e especiação de monilófitas do continente.
No mundo, as monilófitas ocorrem em uma enorme diversidade de habitats, desde o nível do mar até quase o limite da vegetação altimontana nas regiões tropicais, englobando situações subdesérticas como nas caatingas, ambientes salobros como nos manguezais, florestas pluviais tropicais como na planície amazônica, ou pluviais de encosta como nas Serras do Baturité (Estado do Ceará), da Mantiqueira e do Mar (sudeste e sul do Brasil) ou ainda nos Andes, em que as monilófitas vegetam inclusive nos locais mais elevados (Windisch, 1992). 
Por outro lado, as samambaias aquáticas constituem a ordem Salviniales (famílias Marsileaceae e Salviniaceae). Embora elas sejam estruturalmente muito diferentes uma da outra, evidências recentes de análises moleculares indicam que as duas famílias são derivadas de um ancestral terrestre comum (Raven et al., 2014; Gissi, 2016). Além das famílias citadas, há uma terceira família, não enquadrada como samambaia, porém constituída por alguns representantes aquáticos de monilófitas, conhecida como Pteridaceae.

Segundo Neves et al. (2006), ecologicamente as plantas aquáticas, sobretudo as vasculares, incluindose aí as monilófitas, são importantes na produção de matéria orgânica e ciclagem de nutrientes em ambientes lênticos, na produção de alimento para organismos aquáticos e/ou anfíbios, além de servirem como refúgio para diversas espécies de vertebrados e invertebrados nestes ecossistemas. Além de constituírem uma rica fonte de nitrogênio, também atuam como despoluidoras de águas, podendo ser utilizadas no tratamento de esgotos (inclusive para a retirada de metais pesados).

Nos últimos dez anos, foram produzidos estudos sobre distribuição e abundância das licófitas/ monilófitas em várias regiões do Brasil, como por ex. Pereira et al. (2011) em Pernambuco, Schneider \& Schmitt (2011) no Rio Grande do Sul, Pallos et al. (2016) no Pará e Santos et al. (2014) na Bahia. No Nordeste brasileiro, podem ser encontrados vários estudos sobre este grupo de plantas (Pereira et al., 2011; Santiago et al., 2014; Santos et al., 2014; Costa et al., 2018). No Maranhão, as monilófitas estão presentes em poucos estudos científicos, podendo ser citado o estudo produzido por Bastos \& Cutrim (1999), que realizaram o levantamento das pteridófitas presentes na Reserva Ecológica do Sacavém, município de São Luis/MA; o estudo produzido por Conceição \& Ruggieri (2010), que realizaram um levantamento florístico das pteridófitas ocorrentes no município de Tufilândia/ MA; e o estudo realizado por Conceição \& Rodrigues (2010), que levantaram as espécies de pteridófitas do Parque Estadual do Mirador/MA.

Dessa forma, em virtude do escasso conhecimento acerca da flora de monilófitas no Estado do Maranhão bem como da falta de trabalhos enfatizando os grupos de monilófitas aquáticas, o presente trabalho teve como objetivo realizar o levantamento das espécies de monilófitas aquáticas que ocorrem em algumas lagoas da área ItaquiBacanga, município de São Luis.

\section{MATERIAL E MÉTODOS}

\section{Área de estudo}

A pesquisa foi realizada em seis lagoas, duas perenes e quatro temporárias, da Área ItaquiBacanga, Ilha de São Luís-MA. Tais lagoas encontram-se distribuídas ao longo das margens da estrada que corta o setor portuário e industrial.

A área de estudo está localizada no setor oeste do município de São Luís, apresenta as seguintes coordenadas: Lagoa $1\left(02^{\circ} 35^{\prime} 13^{\prime}\right.$ 'S e $\left.44^{\circ} 20^{\prime} 13^{\prime \prime} \mathrm{W}\right)$, Lagoa 2 ( $02^{\circ} 34^{\prime} 22^{\prime \prime}$ S e $\left.44^{\circ} 21^{\prime} 16^{\prime \prime} \mathrm{W}\right)$, Lagoa 3

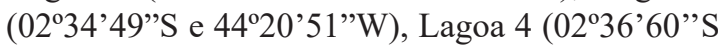

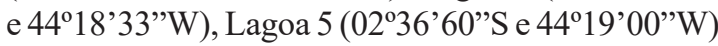
e Lagoa $6\left(02^{\circ} 35^{\prime} 25^{\prime}\right.$ 'S e $\left.44^{\circ} 20^{\prime} 08^{\prime \prime} \mathrm{W}\right)$ (Figura 1).

As lagoas amostradas estão localizadas em uma área de planalto, de relevo ligeiramente suave, distribuídas irregularmente, com intervalos que variam de 1 a $6 \mathrm{~km}$. As suas dimensões variam, aproximadamente, desde os $8 \mathrm{~m}$ aos $100 \mathrm{~m}$ de comprimento máximo. A alimentação dessas lagoas ocorre principalmente pela água da chuva, e, de forma secundária, pelo represamento de pequenas nascentes. A profundidade das lagoas varia de poucos centímetros até cerca de $2 \mathrm{~m}$ (sendo este último valor relacionado às duas lagoas permanentes). Pode ser observado, nesta mesma pesquisa, que a vegetação de macrófitas aquáticas presente nesses sistemas de lagoas compõe-se principalmente das famílias Nymphaeaceae, Araceae, Cyperaceae, Pontederiaceae, Polygonaceae, Salviniaceae e Pteridaceae.

A área Itaqui-Bacanga comporta, além de regiões residenciais (Anjo da Guarda, Mauro Fecury I e II, Vila Maranhão, dentre outras), grandes atividades na área do Distrito Industrial (SEMA, 1997), abrangendo os portos de Itaqui, Ponta da Madeira e Ponta da Espera (Andrade, 2008). Na área de estudo pode ser identificado o domínio de paisagem Planalto Costeiro, com sua unidade de paisagem do tipo Tabuleiro Costeiro. Esta unidade é recoberta por vegetação densa, na qual são abundantes as palmeiras, especialmente o babaçu e a vegetação de porte arbóreo (Legibre, 1994 cit. in Andrade, 2008).

A área Itaqui-Bacanga pertence à bacia de drenagem do rio Bacanga, que possui uma superfície da ordem de 11.030 ha, ocupando a porção Noroeste de São Luís. Os limites são: ao norte, a baía de São Marcos; ao sul, o tabuleiro central da ilha na região do Tirirical; a leste, o divisor de águas que separa as bacias dos rios Anil, Paciência e Tibirí e a oeste, pelo 


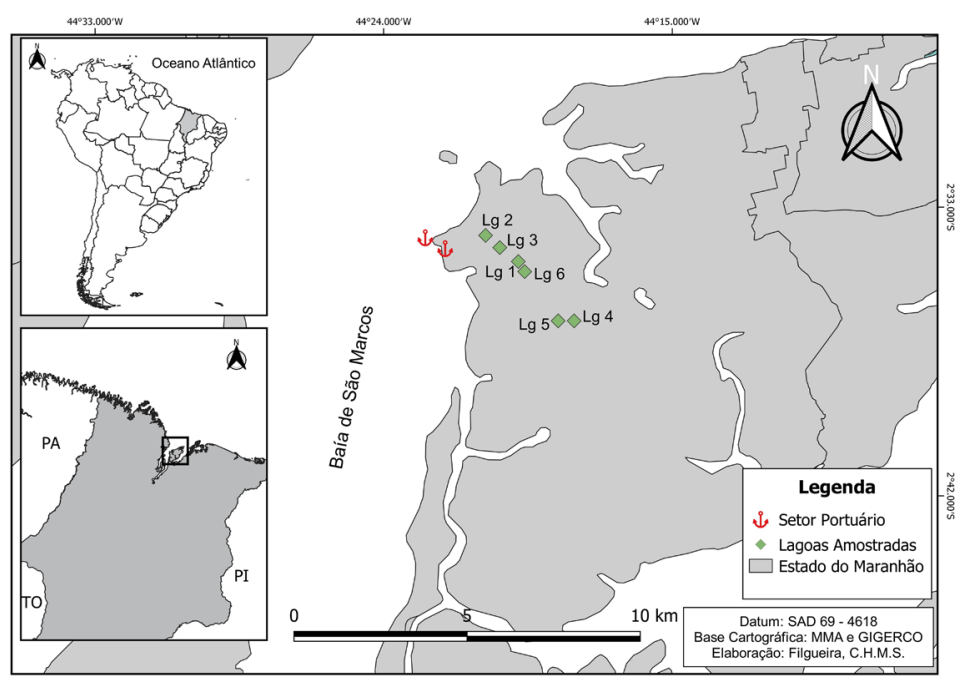

Figura 1. Localização da área de estudo, indicando a disposição das lagoas amostradas ao longo da área Itaqui-Bacanga (São Luís - MA, Brasil).

divisor de águas que separa a Bacia do Bacanga da Bacia Litorânea Oeste (MARANHÃO, 1998).

O Estado do Maranhão localiza-se na faixa de transição entre o clima equatorial e tropical, estando a porção Nordeste do Estado na faixa equatorial e o restante na zona tropical (UEMA, 2016).

Segundo a classificação de Köppen, o clima da Ilha de São Luís é tropical do tipo AW, com verões quentes e úmidos. A média da temperatura mínima é de $29^{\circ} \mathrm{C}$ e a média da temperatura máxima de $31^{\circ} \mathrm{C}$. A pluviosidade média é cerca de $2000 \mathrm{~mm} / \mathrm{ano}$ e ocorrem duas estações bem definidas: a chuvosa, que é caracterizada por apresentar moderados a grandes excedentes hídricos, enchentes dos rios, baixa evaporação, elevada umidade relativa do ar, solos úmidos e temperaturas baixas, que se estende de janeiro a junho; e a seca, caracterizada por déficits de precipitações, altas taxas de evapotranspiração, baixa umidade relativa do ar, solos secos, temperaturas mais elevadas e vazantes dos rios, que vai de julho a dezembro (MARANHÃO, 1998; IBAMA, 2006).

\section{MATERIAL E MÉTODOS}

O levantamento de pteridófitas aquáticas foi realizado no período de junho a setembro de 2011, que corresponde ao final da estação chuvosa e início da estiagem, em seis lagoas. Visitas mensais foram realizadas e foram percorridas as margens das mesmas para observação do habitat e coleta dos organismos vegetais.
O material botânico foi coletado e herborizado de acordo com Fidalgo \& Bononi (1989), seguindo as técnicas usuais de secagem e montagem de exsicatas. O material para o estudo anatômico e morfológico foi fixado com solução de Transeau. $\mathrm{O}$ aspecto geral de cada espécie foi esquematizado e ilustrado.

Depois de fixados os indivíduos, foram feitos cortes anatômicos transversais do caule, estruturas férteis e folhas e, em seguida, foi realizado o tratamento dos mesmos com Hipoclorito de Sódio $(\mathrm{NaClO})$ - para causar o clareamento do tecido e azul de toluidina, para realizar a coloração e evidenciar as estruturas desejadas, tais como feixes vasculares. Para a identificação das espécies, os cortes foram observados em lâminas com o auxílio de microscópio óptico Axiovest-Zeiss e Lupa Zeiss. Para identificação e registro das espécies, foram tiradas fotografias com o auxilio de câmera Fujifilm, modelo A220.

Para identificação do material coletado foi utilizada literatura especializada, tais como os estudos de Gemtchújnicov (1976), Bold et al. (1980), Windisch (1992), Prado (1998), Pott \& Pott (2000), Joly (2002), Neves et al.(2006), Prado (2006) e Pitelli (2006). O sistema de classificação adotado foi o proposto por Tryon \& Tryon (1982). Para se ter segurança sobre a identificação do "Complexo Salvinia auriculata" neste trabalho, foi usada a localização da publicação do Herbário Nacional dos Estados Unidos, onde é feita a distinção entre essa espécie e $S$. rotundifolia. 


\section{RESULTADOS}

No levantamento das monilófitas aquáticas realizado em seis lagoas da Área Itaqui-Bacanga, foram registradas apenas duas famílias, dois gêneros e três espécies. A família com maior representatividade nos ambientes estudados foi Salviniaceae, com duas espécies encontradas e com populações em todas as lagoas amostradas. A família Pteridaceae, em contrapartida, apresentou uma única espécie, de ocorrência em apenas dois dos ambientes amostrados.

O gênero Salvinia apresentou duas espécies (Salvinia auriculata e Salvinia molesta) e o gênero Ceratopteris apresentou apenas a espécie Ceratopteris thalictroides.

Duas formas biológicas de monilófitas foram encontradas nas lagoas: flutuantes livres (Salvinia) e emersas enraizadas (Ceratopteris) (Tabela 1).

A análise da distribuição geográfica das espécies revelou três padrões, um para cada espécie encontrada. Salvinia auriculata apresenta distribuição neotropical, Salvinia molesta a distribuição mundial e Ceratopteris thalictroides tem distribuição pantropical.

\section{Aspectos morfológicos e anatômicos de Salviniaceae}

Salvinia auriculata Aubl., Hist. Pl. Guian. 2: 969. 1775.

Rizoma delgado, com 0,1 cm de diâmetro, apresentando a estrutura (tronco) de onde partem os folíolos submersos, levemente reta ou recurvada para cima, assemelhando-se à forma de "U" em seção transversal. Pecíolo curto, $1 \mathrm{~cm}$ a $2 \mathrm{~cm}$ de comprimento. Frondes flutuantes estéreis, oblongas, com base cordada, levemente pontiagudas a arredondadas na extremidade. Dimensão das frondes flutuantes variando de $1,2 \mathrm{~cm}$ a $2,3 \mathrm{~cm}$ de comprimento e de $1,0 \mathrm{~cm}$ a $2,0 \mathrm{~cm}$ de largura. $\mathrm{Na}$ superfície adaxial, presença de tricomas com quatro ramificações unidas no ápice, em forma de "pá de batedeira" (Figura 2), apresentando comprimento próximo de $680 \mu \mathrm{m}$. A região abaxial apresenta tricomas simples. Venação areolada, sem nervuras no interior das aréolas. Frondes submersas finamente divididas. Presença de indivíduos férteis, contendo microsporângios e megasporângios localizados nos esporocarpos. Estes se diferenciam em forma, apresentando aspecto arredondado (contendo somente megasporângios em pequeno número) e aspecto levemente pontiagudo (contendo somente microsporângios em grande número). Cada microsporângio contém um número grande de micrósporos e cada megasporângio contém um único megásporo. Os esporocarpos são sustentados individualmente por pequenos pecíolos que se desenvolvem a partir das frondes submersas, ficando dispostos na ponta dessas estruturas em um mesmo nível com os demais esporocarpos (Figura 2).

Materiais examinados: 20-VI-2011, L. B. C. Lima (MA); 06-VII-2011, L. B. C. Lima (MA); 20IX-2011, L. B. C. Lima (MA).

Distribuição geográfica: Sul do México, Grandes Antilhas, Trinidad, Colômbia, Argentina e Chile. No Brasil, ocorre em praticamente todo o território, destacando os Estados do Rio de Janeiro, Minas Gerais, São Paulo, Mato Grosso, Mato Grosso do Sul, Pernambuco, Tocantins, Paraná, Amazonas e Maranhão.

A espécie pertence ao denominado "Complexo Salvinia auriculata", que se constitui em um grupo

Tabela 1. Padrões de distribuição geográfica e de forma biológica das monilófitas das lagoas da área Itaqui-Bacanga, São Luis - MA. ( $\mathrm{X}=$ ocorrência do táxon; -= não há registro do táxon).

\section{Famílias/Espécies}

\section{PTERIDACEAE}

Ceratopteris thalictroides (L.) Brongn

SALVINIACEAE

\section{Lagoas de ocorrência}

$$
\begin{array}{llllll}
1 & 2 & 3 & 4 & 5 & 6
\end{array}
$$

\section{Formas biológicas}

$\begin{array}{cll}\begin{array}{c}\text { Hábito e } \\ \text { substrato }\end{array} & \begin{array}{l}\text { Emersa } \\ \text { enraizada }\end{array} & \text { Flutuante } \\ \text { livre }\end{array}$

\section{Distribuição} geográfica
Erva

$$
\mathrm{X}-\mathrm{-} \mathrm{X}-\mathrm{-} \text { aquática }
$$

$$
\text { X }
$$

\begin{tabular}{|c|c|c|c|c|c|c|c|c|c|c|}
\hline Salvinia auriculata Aubl. & - & $\mathrm{X}$ & - & $\mathrm{X}$ & - & $\mathrm{X}$ & $\begin{array}{c}\text { Erva } \\
\text { aquática }\end{array}$ & - & $\mathrm{X}$ & Neotropical \\
\hline $\begin{array}{l}\text { Salvinia molesta D. S. } \\
\text { Mitchell }\end{array}$ & $\mathrm{X}$ & - & $\mathrm{X}$ & - & $\mathrm{X}$ & $X$ & $\begin{array}{c}\text { Erva } \\
\text { aquática }\end{array}$ & - & $\mathrm{X}$ & Mundial \\
\hline
\end{tabular}$$
\text { Pantropical }
$$ 


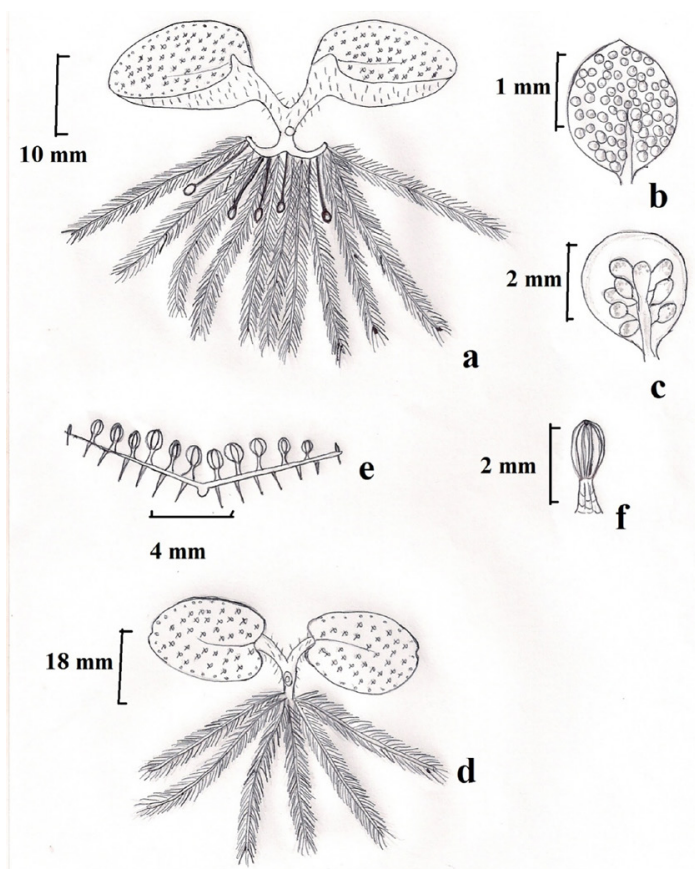

Figura 2. a - Hábito de Salvinia auriculata; b esporocarpo com microsporângios de S. auriculata; c - esporocarpo com megasporângios; d - Hábito de Salvinia molesta; e - seção transversal da fronde flutuante, com destaque aos tricomas ( $S$. auriculata e $S$. molesta) e f - detalhe de um tricoma da face adaxial da lâmina.

restrito formado por quatro espécies de distribuição neotropical, compartilhando o caráter comum de tricomas com aspecto de 'pá de batedeira'. A superfície superior das folhas é recoberta por fileira de tricomas, que apresentam quatro ramificações e são unidos em seu ápice, gerando a citada estrutura. As demais espécies pertencentes ao complexo são: Salvinia biloba Raddi, Salvinia herzogii de la Sota e Salvinia molesta D. S. Mitchell, esta última registrada no presente trabalho.

A seção transversal obtida através do corte do rizoma de S. auriculata Aubl., revelou uma estrutura primária consistindo de epiderme, córtex e estele (Figura 3).

O córtex ocupa a maior parte do rizoma e é composto de aerênquima com 18 câmaras de ar separadas por partições unicelulares não ramificadas, denominadas trabéculas. A endoderme é formada por paredes celulares espessas. A estele é representada por uma camada do periciclo e pelo sistema vascular incorporados ao centro do tecido aerenquimático. O sistema vascular é pouco desenvolvido, sendo composto por elementos do xilema dispostos centralmente e estes, cercados pelo floema. $\mathrm{O}$ feixe vascular formado é do tipo sifonostele.

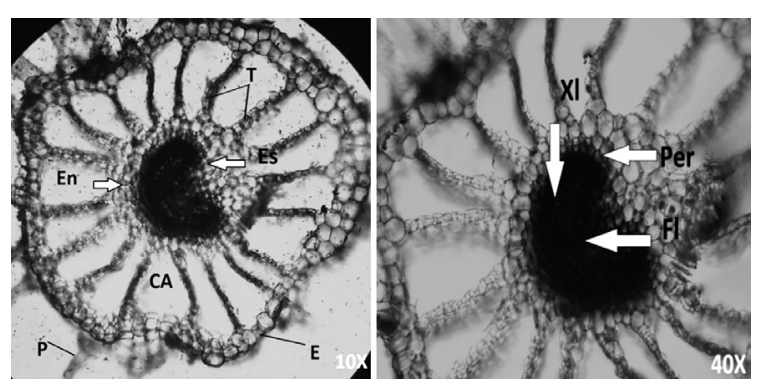

Figura 3. Seção transversal do rizoma de Salvinia auriculata. a - visualização geral da estrutura primária, contendo epiderme, córtex e estele; $\mathrm{b}$ - detalhe da estele: $\mathrm{CA}$ - câmara de ar, E - epiderme, En - endoderme, Es - estele, Fl - floema, $\mathrm{P}$ - pelos, Per - periciclo, T - trabéculas, Xl - xilema.

A seção transversal obtida através do corte da fronde submersa revelou uma estrutura que atua como raiz mantendo, no entanto, sua característica fundamental que a define como uma folha: a capacidade de originar estruturas reprodutivas. O corte da estrutura revelou uma única linha de células epidérmicas conectadas internamente ao córtex (Figura 4). Este último é constituído por tecidos com oito câmaras de ar (aerênquima), separadas por trabéculas. As células epidérmicas possuem uma delgada parede celular, ligeiramente irregular e comportam pêlos com função absorvente (característica similar a das raízes).

A parte central da estele é circundada por 8 células parenquimáticas e sob estas células se encontram o periciclo e o sistema vascular. Este último apresenta o xilema localizado entre os arranjos do floema. De uma forma geral, a estrutura da fronde submersa segue o mesmo padrão encontrado para o rizoma.

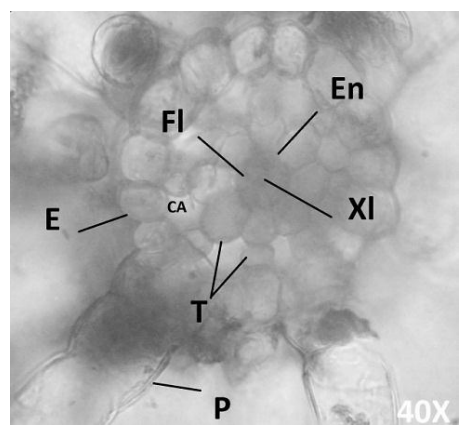

Figura 4. Seção transversal da fronde submersa de Salvinia auriculata. Visualização da epiderme, córtex e estrutura vascular. CA - câmara de ar, E - epiderme, En - endoderme, Fl - floema, P - pelos, T - trabéculas, $\mathrm{Xl}$ - xilema. Xl - xilema. 
Salvinia molesta D. S. Mitchell

Rizoma delgado, comportando em sua extensão pequenos nós, de onde partem as frondes submersas (Figura 2). O talo submerso atinge entre $0,2 \mathrm{~cm} \mathrm{e}$ $0,4 \mathrm{~cm}$ antes de se dividir nos ramos das frondes. Estas apresentam tamanho em torno de $4,0 \mathrm{~cm}$ de comprimento e são finamente divididas em forma de feixes de filamentos. As frondes flutuantes são estéreis, apresentando formato oblongo a ovalado, base cordada, ápice arredondado, apresentando as dimensões $0,9 \mathrm{~cm}$ a $2,3 \mathrm{~cm}$ de comprimento e 0,6 $\mathrm{cm}$ a 2,0 $\mathrm{cm}$ de largura. Presença de tricomas (unidos no ápice) na superfície adaxial da fronde flutuante, possuindo o comprimento próximo de $920 \mu \mathrm{m}$. Região abaxial apresenta tricomas simples dispostos esparsamente. Em colonizações iniciais, as frondes flutuantes apresentam-se levemente achatadas, em contato direto com a superfície da água. No entanto, à medida que o ambiente vai sendo superpovoado, as frondes dobram-se em torno da nervura central, diminuindo a área de contato com a lâmina d'água. No ambiente amostrado, não foram encontradas espécies no estágio de superpopulação. Indivíduos férteis não foram observados para essa espécie, não havendo registros da presença dos esporocarpos.

Materiais examinados: 20-VI-2011, L. B. C. Lima (MA); 5-VII-2011, L. B. C. Lima (MA); 6-VII-2011, L. B. C. Lima (MA), 20-IX-2011, L. B. C. Lima (MA).

Distribuição geográfica: Estados unidos, México, Mesoamérica, Europa (França, Itália e Portugal), África, Oceania e América do Sul (Argentina, Colômbia, Guyana e Brasil). No Brasil, a espécie ocorre predominante nas regiões Sul e Sudeste (Minas Gerais, São Paulo e Paraná), havendo ocorrências no Nordeste para o Estado de Pernambuco e Maranhão.

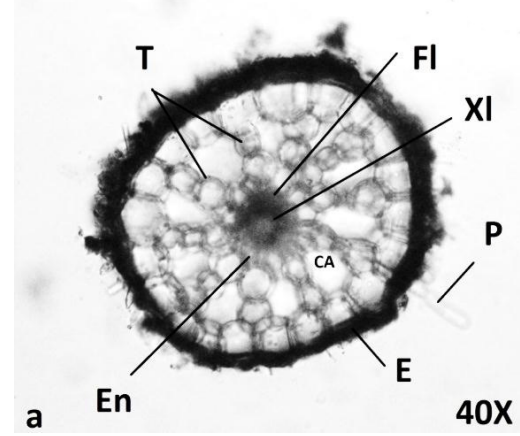

A seção transversal obtida do rizoma de Salvinia molesta D. S. Michell revelou a mesma estrutura padrão primária encontrada para $S$. auriculata, constituída de epiderme, córtex e estele (Figura 5a).

As trabéculas (constituídas por células mais espessas) encontram-se presentes separando as câmaras de ar (aerênquima) em 18 partes. A estele, disposta no centro do tecido aerenquimático, comporta os elementos condutores xilema e floema, dispostos de forma a gerar um feixe vascular sifonostélico, assim como em $S$. auriculata.

A seção transversal das frondes submersas (Figura 5b), seguindo o padrão do rizoma, revelou a ocorrência de células epidérmicas, córtex e estele, seguindo o mesmo padrão anatômico encontrado para S. auriculata. Foram observadas oito câmaras de ar (aerênquima), com grande espaço entre as lacunas, sendo separadas por trabéculas. A estele é constituída células parenquimáticas dispostas em torno do feixe vascular, este último apresenta os elementos condutores xilema e floema.

\section{Pteridaceae}

Os indivíduos pertencentes a esta família apresentam fase esporofítica representada por plantas terrestres, epífitas, rupícolas e aquáticas, possuindo uma grande diversidade em forma e tamanho. Caule curto a longo rastejante, ou inclinado a ereto, apresentando um sifonostelo ou dictiostelo, com folhas espaçadas a fasciculadas, provido de escamas ou tricomas. Presença de folhas monomorfas ou dimorfas, de $3 \mathrm{~cm}$ até $1,5 \mathrm{~m}$, vernação circinada, lâmina inteira, pedada, palmada ou geralmente pinada. Esporângios agrupados em soros, dispostos em linhas ou bandas sobre as nervuras ou na margem dos segmentos laminares (região abaxial), ou ainda,

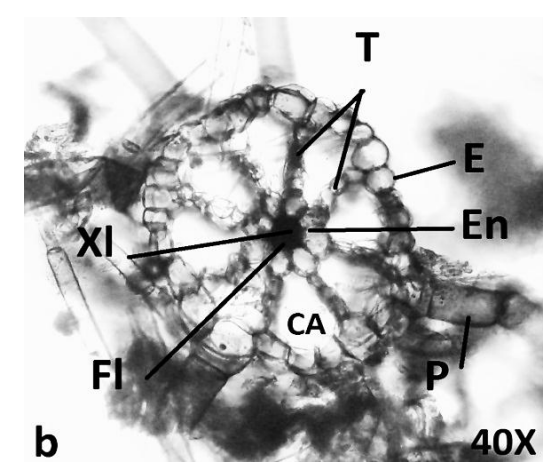

Figura 5. a - seção transversal do rizoma de Salvinia auriculata. Visualização da estrutura primária, contendo epiderme, córtex e estele. b - seção transversal da fronde submersa. Visualização da epiderme, córtex e estrutura vascular. CA - câmara de ar, E - epiderme, En - endoderme, F1 - floema, P - pelos, T - trabéculas, X1 - xilema. 
distribuídos sem padrão definido. Indúsio presente ou ausente, formado na margem da lâmina recurvada, delgada. Os esporângios geralmente apresentamse pedicelados ou curto-pedicelados, ocorrendo isosporia. Esporos triletes, sem clorofila. Fase gametofítica epígea, clorofilada, talo obcordado a reniforme, algumas vezes assimétrico.

Pteridaceae é uma família que apresenta distribuição quase cosmopolita, com aproximadamente 35 gêneros e, destes, 22 ocorrem na América. Dos gêneros pertencentes a esta família, apenas um é aquático (Ceratopteris), com ocorrência registrada para a área do presente estudo.

\section{Ceratopteris Brongn.}

Plantas aquáticas ou semi-aquáticas de até $1 \mathrm{~m}$ de altura, enraizadas ou flutuantes. Caule ereto ou horizontal, esparsamente escamoso, escamas largas, castanho-claras e escuras. Folhas dimorfas, com até $40 \mathrm{~cm}$ de comprimento, pecíolo herbáceo, frequentemente inflado, achatado quando seco. Folhas estéreis com lâminas simples a tripinadas; as compostas terminando num ápice pinafítico, frequentemente provido de gemas distribuídas nas axilas das pinas. Folhas férteis 3-5 pinadas, maiores que as estéreis, segmentos terminais lineares, agudos, enrolados sobre si mesmos de forma a incluir diversas fileiras de esporângios. Estes últimos situam-se abaxialmente ao longo de nervuras longitudinais, não sendo agrupados em soros individualizados e apresentando ânulo longitudinal. O indúsio é ausente. $\mathrm{O}$ gênero ocorre nas regiões tropical e subtropical do globo.

Ceratopteris thalictroides (L.) Brongn., Bull. Sci. Soc. Philom. Paris. sér. 3, 8: 186. 1821.

Erva aquática enraizada, 60 a $70 \mathrm{~cm}$ de comprimento. Caule ereto, espesso, apresentando $0,6 \mathrm{~cm}$ de largura. Folhas estéreis com lobos lineares oblongos a elípticos, glabras, com pecíolos de 5 a $8 \mathrm{~cm}$, bipinadas e tripinadas, apresentando $3 \mathrm{~cm}$ de largura e $10 \mathrm{~cm}$ de comprimento. Folhas férteis lanceoladas a ovaladas, apresentando 3 a 4 pinas proximais e 2 pinas distais, glabras, dimensões médias de $4 \mathrm{~cm}$ de comprimento e 0,2 de largura, com pecíolos de 12 a $13 \mathrm{~cm}$. Apresenta homosporia. Esporângios localizados abaxialmente nas margens revolutas das pinas férteis (Figura 6), distribuídos individualmente ao longo das mesmas. Os esporos apresentam aspecto tetraédrico.

Materiais examinados: 20-VI-2011, L. B. C. Lima (MA); 06-VII-2011, L. B. C. Lima (MA).

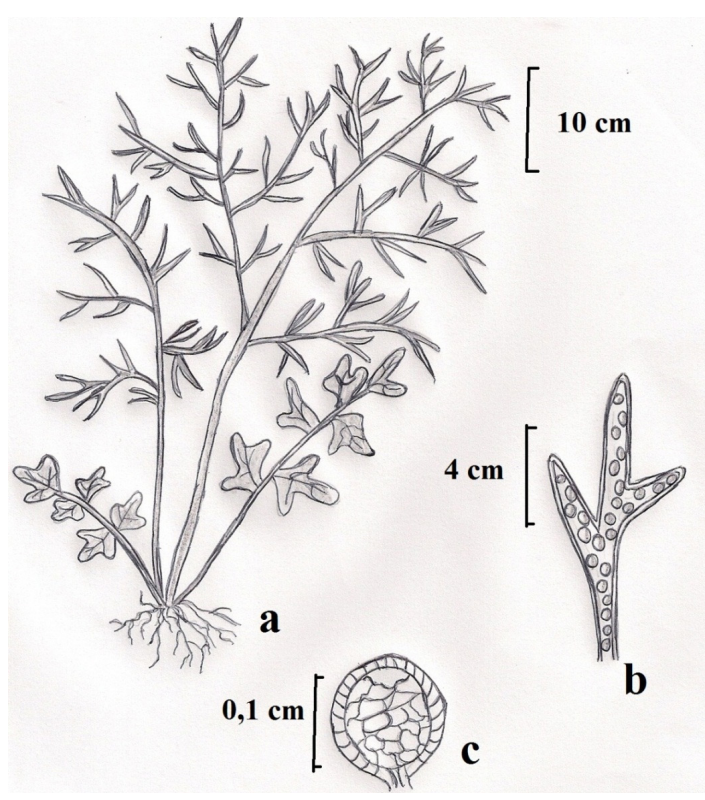

Figura 6. a - Hábito de Ceratopteris thalictroides com duas folhas muito divididas; b - detalhe de pinas férteis, com visualização dos esporângios protegidos pelo enrolamento das margens e c - detalhe de um esporângio.

Distribuição geográfica: Sudeste da Ásia, Norte da Austrália, Leste da África, Sul dos Estados Unidos e América do Sul. No Brasil, ocorre nos Estados do Rio de Janeiro, Mato Grosso, Pernambuco e Maranhão.

A seção transversal obtida através do corte do caule de Ceratopteris thalictroides revelou vários anéis concêntricos de feixes vasculares isolados, semelhantes entre si na forma e espessura. Tais feixes vasculares organizam-se esparsamente ao longo do caule, e cada feixe contém xilema e floema. $\mathrm{O}$ córtex ocupa a maior parte do caule e é composto por aerênquima distribuído de forma irregular ao redor dos feixes vasculares (Figura 7). O feixe vascular formado é do tipo eustele.

\section{DISCUSSÃO}

As Monilophyta das seis lagoas apresentaram uma distinção entre si, especialmente quanto à espécie Ceratopteris thalictroides, que apareceu em duas lagoas somente e apresentando um indivíduo só em cada uma. Entre as espécies registradas, Salvinia molesta foi a mais freqüente nos ambientes estudados, apresentando grande povoamento, ocorrendo desde o centro até as margens das lagoas, muitas vezes alternando-se entre outras plantas aquáticas, tais como Pistia stratiotes (família Araceae). Pitelli (2006), observando situação 


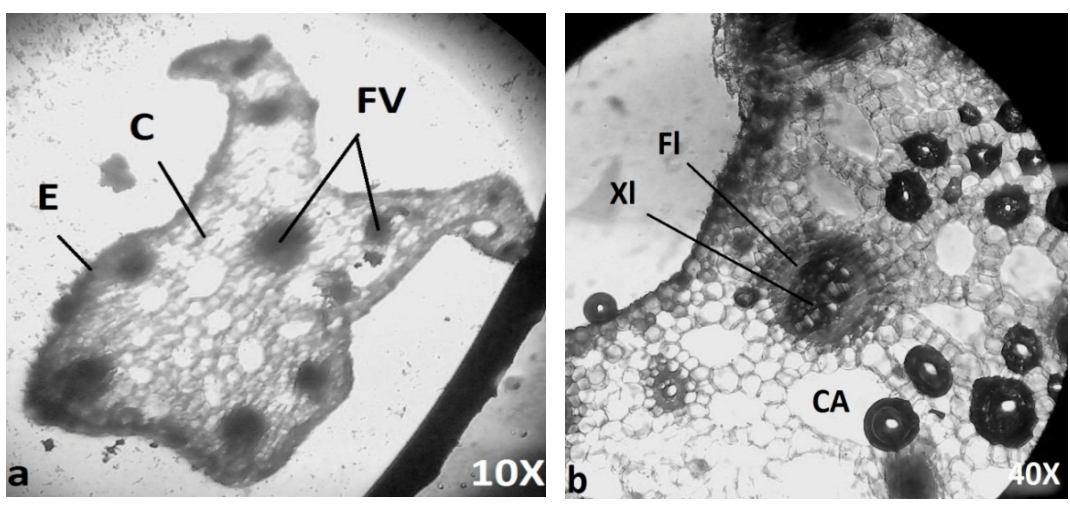

Figura 7. Seção transversal do caule de Ceratopteris thalictroides. a - visualização geral da estrutura contendo a epiderme, córtex e os feixes vasculares e b - detalhe dos feixes vasculares. C - córtex, CA - câmara de ar, E - epiderme, Fl - floema, FV - feixes vasculares e X1 - xilema.

semelhante no levantamento de macrófitas aquáticas em um reservatório do Rio de Janeiro, afirmou que a distribuição geográfica das populações pertencentes ao gênero Salvinia sempre foi do tipo casualizado, sendo este comportamento explicado pelas características morfológicas destas plantas, como o pequeno porte, estruturas modificadas semelhantes a raízes em pequeno tamanho, folhas se distribuem de forma a facilitar a dispersão da planta pelo vento e a sua reprodução de forma vegetativa facilita a fragmentação dos rizomas gerando novos indivíduos, que se deslocam facilmente no ambiente podendo se localizar de forma entremeada com outras populações de maior porte. Salvinia molesta é reportada por Araújo et al. (2007) como uma das macrófitas aquáticas mais frequentemente associadas a problemas de superpopulação.

Os trabalhos que se reportam à ocorrência de espécies de Salvinia são basicamente direcionados ao estudo de represas e reservatórios. Podem ser citados os trabalhos de Araújo et al. (2007), que estudaram o comportamento sazonal da espécie S. molesta em dois açudes em Pernambuco, encontrando um comportamento sazonal semelhante para a espécie ao longo do ano, apesar das diferenças geográficas entre os ambientes amostrados. No presente trabalho, o padrão sazonal encontrado para a espécie $S$. molesta foi similar ao encontrado por este autor, não havendo grande variação sazonal para a distribuição da espécie entre os ambientes observados. A distribuição de Salvinia nos ambientes pesquisados parece estar ligada mais ao prolongamento do período chuvoso e ao nível de água nas lagoas. Pelli \& Barbosa (2011), estudando a herbivoria de $S$. molesta em uma lagoa de Minas Gerais, também registraram a ocorrência da espécie durante o ano inteiro.

Tanaka et al. (2002), através de um levantamento da ocorrência de plantas aquáticas nos reservatórios da Companhia Energética de São Paulo, encontraram a espécie Salvinia molesta como uma das mais frequentes nas áreas estudadas.

No presente trabalho, Salvinia auriculata se fez presente em três (50\%) das lagoas observadas, apresentando um padrão de distribuição de cobertura da lâmina d'água semelhante ao encontrado para S. molesta, ou seja, as duas espécies ocorreram associadas. Para a ocorrência da espécie $S$. auriculata, existem muitos estudos em várias regiões do país. Martins et al. (2003) registraram a espécie em levantamentos das plantas aquáticas nos reservatórios do Rio de Janeiro, apresentando tal espécie a segunda maior ocorrência na cobertura da área amostrada. Bianchini et al. (2010), realizando o monitoramento de um reservatório em Tocantins, encontraram $S$. auriculata recobrindo grande parte da área estudada, principalmente localizada em áreas protegidas da ação do vento e das correntezas.

No Maranhão, o trabalho de Fernandes et al. (2010) no município de Caxias foi o primeiro a reportar a ocorrência de $S$. auriculata para o Estado, sendo a única espécie de monilófita aquática registrada para a área. Segundo os mesmos autores, a espécie ocorreu em ambientes lamosos de águas rasas, sendo representada por poucos indivíduos. A espécie $S$. auriculata também foi registrada nos trabalhos de Santos et al. (2004) para o Rio de Janeiro, Santiago (2006) e Barros \& Xavier (2007) para Pernambuco, Sakagami (2006) para o Paraná, Prado (2006) para São Paulo e Filho \& Windisch (2006) para o Rio Grande do Sul.

Ceratopteris thalictroides apresentou poucos indivíduos nas lagoas estudadas, sendo observada em duas lagoas e, em cada uma delas, foi encontrado apenas um único indivíduo. Fernandes et al. (2010), 
realizando o inventário das samambaias e licófitas do município de Caxias-MA, também reportaram a ocorrência da espécie e apenas um indivíduo, sendo este encontrado em ambientes alagados próximos a buritizais. Ainda no Maranhão, Conceição \& Ruggieri (2010) realizaram um levantamento das monilófitas do município de Tufilândia e verificaram que a espécie $C$. thalictroides foi a única deste grupo encontrada em ambiente aquático na área amostrada. Além dos trabalhos anteriormente citados, poucos registros pelo país reportam a ocorrência da espécie, podendo ser citados os trabalhos de Santos et al. (2004), que observaram C. thalictroides em um ambiente de restinga no Rio de Janeiro; Moreira \& Bove (2008), que realizaram o levantamento das plantas aquáticas do Horto Botânico do Museu Nacional do Rio de Janeiro; Santiago (2006), que realizou o levantamento da flora de monilófitas presente na Floresta Atlântica, ao Norte do rio São Francisco, França et al. (2010), o levantamento florístico das espécies de macrófitas aquáticas do baixo São Francisco; e Rocha (2006), que realizou o levantamento das plantas aquáticas do Pantanal.

Apesar da ocorrência dos grupos de Ceratopteris e Salvinia registrada para algumas regiões do país, na ilha de São Luís não havia registros desses grupos.

Ambos os gêneros encontrados são grupos de monilófitas anuais ou perenes de curta duração, isto é, são tipos de plantas que normalmente germinam, crescem e morrem completando o seu ciclo de vida num ano ou menos (Cook, 1974). A espécie $C$. thalictroides apresenta um ciclo de vida relativamente curto, podendo ser concluído em menos de 30 dias. Ainda segundo este autor, além da reprodução por esporos, a espécie se multiplica por gemiparidade, com mudas aparecendo na extremidade das folhas mais antigas.

A presença de um aerênquima bem desenvolvido nos caules da espécie Ceratopteris thalictroides permite que esta realize suas trocas gasosas, além de manter a flutuação (estabilidade) no ambiente aquático, uma vez que a presença das câmaras de ar no interior da planta a torna mais leve, favorecendo a sua sustentação na água. No que diz respeito à estrutura das folhas nas monilófitas observadas, ambos os gêneros (Salvinia e Ceratopteris) apresentam um padrão de folhas dimorfas, ou seja, há a presença bem definida de folhas com a função de reprodução, chamadas esporófilos, e as folhas com a função de assimilação, chamadas trofófilos (Schultz, 1980). Nas espécies de Salvinia, as folhas férteis são submersas, semelhantes a raízes, apresentando as funções de produzir os esporângios, assimilar nutrientes e ainda de manter a estabilidade da planta. Em Ceratopteris, as folhas férteis, localizadas normalmente fora da água (emersas), apenas comportam os esporângios, estando estes localizados nas margens revolutas da face abaxial da planta.

Dentre as monilófitas amostradas, apenas o gênero Salvinia apresenta heterosporia, com a presença de megasporângios e microsporângios. O gênero Ceratopteris, por sua vez, é homosporado, apresentando apenas esporos masculinos, que possuem um potencial para desenvolver gametófitos que futuramente poderão ser masculinos ou hermafroditas.

Como disseram Mickel \& Smith (2004), Salvinia é um gênero inconfundível pelas suas folhas flutuantes pequenas, arredondadas a oblongas, e pelas folhas submersas semelhantes a raízes com esporocarpos. Neste trabalho, os tricomas são considerados estruturas importantes para a distinção das espécies, bem como de alta funcionalidade na flutuação das plantas. Barthlott et al. (2009) evidenciaram a importância dos tricomas de Salvinia para a diferenciação sistemática, flutuabilidade vegetal e na hidrofobia das folhas às gotículas de água. Por outro lado, Gorb \& Speck (2017), em um estudo de nanotecnologia sobre estruturas de organismos, comentam que não somente as samambaias flutuantes do genero Salvinia, mas também outros organismos flutuantes ou que mergulham (e.g., algumas espécies de aranhas e besouros bem como algumas aves e mamíferos), tipicamente possuem estruturas capilares em dupla face, flexíveis, nas suas superfícies externas que podem aprisionar uma camada de ar sob a água por períodos de vários minutos, dias e mesmo meses. A importância biológica dessas camadas de ar pode ser flutuação, isolamento, suprimento de oxigênio durante o mergulho e/ou fricção-redução durante o mergulho ou natação.

Segundo Mickel \& Smith (2004), o habitat em que essas plantas ocorrem é um forte influenciador sobre as modificações nas estruturas vegetativas e reprodutivas que apresentam, não se assemelhando às estruturas de outras monilófitas.

A ocorrência de ambas as espécies de Salvinia nas lagoas se deve, em grande parte, à interferência antrópica, que causa um aumento da disponibilidade de nutrientes nos corpos d'água, criando condições favoráveis ao seu desenvolvimento (Sakagami, 2006; Boschilia, 2006). Tais ambientes, devido ao fato de se localizarem em zona de fácil acesso ao longo da estrada, tornam-se o receptáculo de dejetos sólidos, além de receber por meio do escoamento 
superficial, dejetos líquidos provenientes da lixiviação do solo e asfalto das proximidades, fontes que foram observadas nas proximidades das lagoas, influenciando a propagação vegetativa dessas plantas, apresentando altas taxas de crescimento e capacidade de reprodução em um curto período de tempo, colonizando assim, grandes superfícies.

Embora poucos estudos abordem a ocorrência de monilófitas aquáticas no Estado do Maranhão, muito pode ser feito para que se conheça essa flora local, uma vez que vários trabalhos indicam que tais espécies apresentam ampla ocorrência nos corpos d'água, muitas vezes apresentando dominância em relação a outros grupos botânicos aquáticos.

\section{REFERÊNCIAS BIBLIOGRÁFICAS}

ANDRADE, M.M.N. 2008. Mapeamento das unidades de paisagem, da sensibilidade ambiental e da vulnerabilidade social na área do porto de ItaquiBacanga, Ilha de São Luís, MA. 133 p. Dissertação (Mestrado em Geologia e Química) - Universidade Federal do Pará, Belém.

ARAÚJO, P.O.; NASCIMENTO, P.R.F. \& PEREIRA, S.M.B. 2007. Comparação da biomassa da planta aquática daninha Salvinia molesta Mitchell registrada na Região Metropolitana do Recife e Zona da Mata em Pernambuco, Brasil. In: Congresso de Ecologia do Brasil, VIII. Caxambu, Anais.

BARROS, I.C.L., SANTIAGO, A.C.P.; XAVIER, S.R.S.; PIETROBOM, M.R. \& LUNA, C.P.L. 2002. Diversidade e aspectos ecológicos das pteridófitas (avencas, samambaias e plantas afins) ocorrentes em Pernambuco, p. 153-171. In: M. Tabarelli \& J.M.C. Silva. (Eds), Diagnóstico da Biodiversidade de Pernambuco. v. 1. Recife, Ed. Mas-sangana e SECTMA.

BARROS, I.C.L. \& XAVIER, S.R.S. 2007. Salviniaceae do Estado de Pernambuco, Brasil. Rev. Bras. de Biociências. 5(2): 246-248.

BARTHLOTT, W.; WIERSCH, S.; OLI, Z.; KOCH, K. 2009. Classification of trichome types within species of the water fern Salvinia, and ontogeny of the egg-beater trichomes. Botany. 87(9): 830-836

BASTOS, C.C.C. \& CUTRIM, M.V.J. 1999. Pteridoflora da Reserva Florestal do Sacavém, São Luis-MA. Boletim Museu Paraense Emílio Goeldi. 15(1): 1-37.

BIANCHINI, I.; CUNHA-SANTINO, M.B.; \& FUSHITA, A.T. 2010. Monitoramento das Macrófitas
Aquáticas do Reservatório da Usina Hidrelétrica Luís Eduardo Magalhães (Estado de Tocantins, Brasil). Augmdomus. 2: 38-48.

BOLD, H.C.; ALEXOPOUlos, C.J. \& DELEVORYAS, T. 1980. Morphology of plants and fungi. 4 ed. New York: Litthograph. p. 280-418.

BOSCHILIA, S.M.; THOMAZ, S.M. \& PIANA, P.A. 2006. Plasticidade morfológica de Salvinia herzogii (de La Sota) em resposta à densidade populacional. Acta Sci. Biol. Sci. 28(1): 35-39.

CONCEIÇÃO, G.M. \& RODRIGUES, M.S. 2010. Pteridófitas do Parque Estadual do Mirador, Maranhão, Brasil. Cadernos de Geociências, $\mathrm{n}^{\mathrm{0}} 7$, maio.

CONCEIÇÃO, G.M. \& RUGGIERI, A.C. 2010. Pteridófitas do município de Tufilândia, Estado do Maranhão, Brasil. Pesquisa em Foco. 18(1): 59-68.

COOK, C.D.K. 1974. Water plants of the world: a manual for the identification of the genera of freshwater macrophytes. New York: Springer. 591p.

COSTA, L.E.N.; FARIAS, R.P.; SANTIAGO, A.C.P.; SILVA, I.A.A. \& BARROS, I.C.L. 2018. Abiotic factors drives floristic variations of fern's metacommunity in an Atlantic Forest remnant. Brazilian Journal of Biology. 78(4): 736-741.

FERNANDES, R.S.; CONCEIÇÃO, G.M.; COSTA, J.M. \& PAULA-ZÁRATE, E.L. 2010. Samambaias e licófitas do município de Caxias, Maranhão, Brasil. Bol. Mus. Para. Emílio Goeldi. Cienc. Nat.. 5(3): 345-356.

FIDALGO, O. \& BONONI, V.L.R. 1989. Técnica de coleta, preservação e herborização de material botânico. (Série Documentos, manual no 4). Instituto de Botânica/Secretaria do Meio Ambiente. São Paulo. 61p

FILHO, F.P.A. \& WINDISCH, P.G. 2006. Florística e aspectos ecológicos das pteridófitas em uma floresta de Restinga no estado do Rio Grande do Sul, Brasil. Iheringia, Sér. Bot. 61(1-2): 63-71.

FORNO, I.W. 1983. Native distributions of the Salvinia auriculata complex and keys to species identification. Aquatic Botany. 17: 71-83.

FRANÇA, C.R.C.; FREIRE, D.O. \& SANTOS, V.V. 2010. Macrófitas aquáticas da região do baixo Rio São Francisco, Brasil. Recife: JEPEX.

GEMTCHÚJNICOV, I.D. 1976. Manual de taxonomia vegetal: plantas de interesse econômico. 
São Paulo: Ed. Agronômica Ceres. 368p. (Ceres, 16)

GISSI, D.S. 2016. Samambaias e Licófitas: as plantas vasculares sem sementes. https://www.researchgate. net/publication/308971897_Samambaias_e_ Licofitas_As_plantas_vasculares_sem_sementes (consultada em 18/02/2020).

GORB, S. \& SPECK, T. 2017. Biological and biomimetic materials and surfaces. Beilstein J. Nanotechnol. 8: 403-407.

IBAMA. 2006. Laudo Sócio-Econômico e Biológico Para Criação da Reserva Extrativista do Taim. São Luís. 194p.

JOLY, A.B. 2002. Introdução à taxonomia vegetal. 13 ed. São Paulo: Companhia Editora Nacional. 134-186 p.

LEGIBRE, J.M. 1994. Les marais maritimes de la baie de São Marcos (Maranhão-Brésil). In: ANDRADE, M.M.N. 2008. Mapeamento das unidades de paisagem, da sensibilidade ambiental e da vulnerabilidade social na área do porto de ItaquiBacanga, Ilha de São Luís, MA. 133 p. Dissertação (Mestrado em Geologia e Química) - Universidade Federal do Pará, Belém.

LEWINSOHN, T.M. \& PRADO, P.I. 2002. Biodiversidade Brasileira: Síntese do Estado Atual do Conhecimento. São Paulo: Editora Contexto.

MARANHÃO. 1998. Secretaria de Estado do Meio Ambiente e Recursos Hídricos. Coordenadoria de Programas Especiais. Programa Estadual de Gerenciamento Costeiro. Macrozoneamento do Golfão Maranhense. Diagnóstico Ambiental da Microrregião da Aglomeração Urbana de São Luís e dos Municípios de Alcântara, Bacabeira e Rosário. Estudo Sócio-Ambiental. São Luís: Sema/MMA/ PNMA.

MARTINS, D.; VELINI, E.D.; PITELLI, R.A.; TOMAZELLA, M.S. \& NEGRISOLI, E. 2003. Ocorrência de plantas aquáticas nos reservatórios da Light-RJ. Planta Daninha. 21: 105-108.

MICKEL, J.T. \& SMITH, A.R. 2004. The pteridophytes of Mexico. In: PRADO, J. 2006. Criptógamos do Parque Estadual das Fontes do Ipiranga, São Paulo, SP. Pteridophyta: 18. Salviniaceae. Hoehnea. 33(1): 107-110.

MOREIRA, A.D.R. \& BOVE, C.P. 2008. Plantas aquáticas do Horto Botânico do Museu Nacional do Rio de Janeiro. Arquivos do Museu Nacional. 66(3-4): 459-476.
NEVES, E.L.; LEITE, K.G.B.; FRANÇA, F. \& MELO, E. 2006. Plantas aquáticas vasculares em uma lagoa de planície costeira do município de Candeias, Bahia, Brasil. Sitientibus. 6(1): 24-29.

PALLOS, J.; GÓES-NETO, L.A.A.; COSTA, J.M.; SOUZA, F.S.; PIETROBOM, M.R. 2016. Licófitas e samambaias da Serra do Itauajuri, município de Monte Alegre, Pará, Brasil. Rodriguésia. 67(4): 997-1009.

PELLI, A. \& BARBOSA, F.A.R. 2011. Herbivoria em Salvinia molesta Mitchell em um lago do Planalto kárstico de Lagoa Santa, Minas Gerais. Brasil. Rev. Saúde e Biol. 6(1): 60-66.

PEREIRA, A.B. 2003. Introdução ao estudo das pteridófitas. $2^{\mathrm{a}}$ ed. Canoas: Ed. ULBRA. 92 p.

PEREIRA, A.F.N.; BARROS, I.C.L.; SANTIAGO, A.C.P.; SILVA, I.A.A. 2011. Florística e distribuição geográfica das samambaias e licófitas da Reserva Ecológica de Gurjaú, Pernambuco, Brasil. Rodriguésia. 62(1): 1-10.

PIETROBOM, M.R. \& BARROS, I.C.L. 2003. Pteridófitas de um fragmento florestal na Serra Mascarenhas, estado de Pernambuco, Brasil. Insula. 32: 73-118.

PITELLI, R.L.C.M. 2006. Abordagens multivariadas no estudo da dinâmica de comunidades de macrófitas aquáticas. 67 p. Tese (Doutorado em Agronomia) Universidade Estadual Paulista Júlio de Mesquita Filho, Botucatu.

POTT, V.J. \& POTT, A. 2000. Plantas aquáticas do Pantanal. Brasília: EMBRAPA. 404 p.

PRADO, J. 1998. Pteridófitas do Estado de São Paulo. In: BICUDO, C.E.M. \& SHEPHERD, G.J. 1998. Fungos macroscópicos e plantas do Estado de São Paulo (Série Biodiversidade do Estado de São Paulo). São Paulo: FAPESP. v. 2, p. 49-61.

PRADO, J. 2005. Pteridaceae da Reserva Ecológica de Macaé de Cima, Nova Friburgo, Rio de Janeiro, Brasil. Rodriguésia. 56(87): 179-184.

PRADO, J. 2006. Criptógamos do Parque Estadual das Fontes do Ipiranga, São Paulo, SP. Pteridophyta: 18. Salviniaceae. Hoehnea. 33(1): 107-110.

RAVEN, P.H.; EVERT, R.F. \& EICHHORN, S.E. 2014. Biologia Vegetal. Rio de Janeiro: Guanabara Koogan. 416 p.

ROCHA, L.A. 2006. Espécies de plantas aquáticas no Pantanal. 55 p. Monografia (Graduação em 
Ciências Biológicas) - Universidade de Cuiabá, Cuiabá.

SAKAGAMI, C.R. 2006. Pteridófitas do Parque Ecológico da Klabin, Telêmaco Borba, Paraná, Brasil. 212 p. Dissertação (Mestrado em Botânica) - Universidade Federal do Paraná, Curitiba.

SANTIAGO, A.C.P. 2006. Pteridófitas da floresta atlântica ao norte do rio São Francisco: florística, biogeografia e conservação. 146 p. Tese (Doutorado em Biologia Vegetal) - Universidade Federal de Pernambuco, Recife.

SANTIAGO, A.C.P.; BARROS, I.C.L.; DITTRICH, V.A.O. 2014. Samambaias e licófitas do estado de Pernambuco, Brasil: Blechnaceae. Rodriguésia. 65(4): 861-869

SANTOS, M.G.; SYLVESTRE, L.S. \& ARAUJO, D.S.D. 2004. Análise florística das pteridófitas do Parque Nacional da Restinga de Jurubatiba, Rio de Janeiro, Brasil. Acta Bot. Bras. 18(2): 271-280

SCHNEIDER, P.H. \& SCHMITT, J.L. 2011. Composition, community structure and vertical distribution of epiphytic ferns on Alsophila setosa Kaulf., in a Semideciduous Seasonal Forest, Morro Reuter, RS, Brazil. Acta Bot. Bras. 25(3): 557-565.

SCHULTZ, A.R.H. 1980. Introdução à botânica sistemática. 5 ed. Porto Alegre: Ed. da Universidade Federal do Rio Grande do Sul. 294p.

SEMA - Secretaria de Estado do Meio Ambiente e Recursos Hídricos. Programa Estadual de Gerenciamento Costeiro. 1997. Macrozoneamento diagnóstico ambiental da microregião de aglomeração urbana de São Luís. Estudo de ocupação espacial e cobertura da terra. São Luís: SEMA/GERCO. 137 p.

TANAKA, R.H.; CARDOSO, L.R.; MARTINS, D.; MARCONDES, D.A.S. \& MUSTAFÁ, A.L.V. 2002. Ocorrência de plantas aquáticas nos reservatórios da Companhia Energética de São Paulo. Planta Daninha. 20:101-111.

TRYON, R.M. \& TRYON, A.F. 1982. Ferns and allied plants with special reference to Tropical America. In: CONCEIÇÃO, G.M. \& RUGGIERI, A.C. 2010. Pteridófitas do município de Tufilândia, Estado do Maranhão, Brasil. Pesquisa em Foco. 18(1): 59-68.

TRYON, R.M. \& TRYON, A.F. 1982. Ferns and allied plants. In: PEREIRA, A.B. 2003. Introdução ao estudo das pteridófitas. 2 ed. Canoas: Ed. ULBRA. $192 \mathrm{p}$.

VAN DER BURG, W.J. 2004. Ceratopteris thalictroides (L.) Brongn. Disponível em: <http:// database.prota.org/dbtw-wpd/exec/dbtwpub. $\mathrm{dll} ? \mathrm{ac}=\mathrm{qbe} \_q u e r y \& b u=\mathrm{http}: / /$ database.prota.org/ search.htm\&tn $=$ protab $1 \& q b 0=$ and $\& q f 0=$ Species ${ }^{+}$ Code \&qi $0=$ Ceratopteris + thalictroides $\& \mathrm{rf}=$ Webdis play>. Acesso em: 19 out. 2011.

WINDISCH, P.G. 1992. Pteridófitas da região norte-ocidental do Estado de São Paulo: guia para estudo e excursões. 2 ed. São José do Rio Preto: UNESP. $110 \mathrm{p}$.

ZUQUIM, G.; COSTA, F.R.C.; PRADO, J. \& TUOMISTO, H. 2008. Guia de samambaias $e$ licófitas da REBIO Uatumã, Amazônia Central. Manaus: Áttema Design Editorial. 316 p. 